\title{
Airway dynamics, oesophageal pressure and cough
}

\author{
M.H. Lavietes*, S.C. Smeltzer**, S.D. Cook*, R.M. Modak*, G.C. Smaldone+
}

\begin{abstract}
Airway dynamics, oesophageal pressure and cough. M.H. Lavietes, S.C. Smeltzer, S.D. Cook, R.M. Modak, G.C. Smaldone. OERS Journals Ltd 1998.

ABSTRACT: This study hypothesizes that: peak supramaximal airflow during cough reflects expiratory muscle effort, and that expiratory muscle function during cough might be assessed from the airflow signal alone.

We monitored airflow and oesophageal pressure $\left(P_{0 e s}\right)$ in normal subjects during cough generated under two conditions: 1) voluntarily from functional residual capacity (FRC); and 2) involuntarily after inhalation of citric acid (CA). Maximal expiratory cough flow was quantified as the quotient of maximal flow during a given cough divided by maximal flow at the matched volume of thoracic gas $(V \mathrm{tg})$ as identified on the maximal expiratory flow-volume curve.

We found: flow ratios correlated poorly with $P_{0 e s}$; the variance of flow ratios associated with a series of voluntary coughs was poorly explained by $P$ oes. During CA inhalation, when the $V$ tg compressed during cough could not be controlled, correlation of $P$ oes with flow ratio remained poor.

We conclude that to study the motor limb of the cough reflex, measurements of both airflow and oesophageal pressure are required.

Eur Respir J 1998; 11: 156-161.
\end{abstract}

\begin{abstract}
*The Division of Pulmonary and Critical Care Medicine and the Dept of Neurosciences, New Jersey Medical School, Newark. **The Dept of Nursing, Thomas Jefferson University, Philadelphia, PA, and the Division of Pulmonary and Critical Care Medicine, State University of New York at Stony Brook, Stony Brook, NY, USA.

Correspondence: M.H. Lavietes, University Hospital (I-354), 100 Bergen Street, Newark, New Jersey 07103,USA.

Fax: 0019739726228

Keywords: Citric acid, citric acid induced cough, cough, cough reflex, oesophageal pressure, respiratory muscles

Received: August 141996

Accepted after revision August 311997

Supported by grants from the Eastern Paralyzed Veterans' Association and Biomedical Research Grant, of Rutgers University.
\end{abstract}

The afferent limb of the cough reflex has been well studied [1]. By contrast, the efferent limb of the cough reflex has not been studied in a systematic fashion. Airflow during cough has been studied using the standard format of the maximal expiratory flow-volume (MEFV) curve [2]. Such analysis has suggested that effective cough occurs after the development of sufficient positive intrapleural pressure during the compressive phase of cough such that tracheal compression and, transiently, a burst of supramaximal airflow follow glottal opening. Inability to develop this transient supramaximal flow is seen in both curarized normal volunteers and patients with muscular dystrophy [3, 4]. In this study, we explore the possibility that a quantitative analysis of the peak supramaximal flow during cough might reflect the quantity of pressure or force generated by expiratory muscles during cough [5].

\section{Materials and methods}

\section{Subjects}

Five healthy subjects participated and signed informed consent. Spirometry and functional residual capacity (FRC), measured by helium dilution, were obtained with standard laboratory equipment (DSII Plus; WE Collins, Braintree, MA, USA). Predicted values for lung volumes were those of the Intermountain Thoracic Society [6].

\section{Procedure}

Subjects sat quietly and comfortably. Each wore a noseclip and breathed via a wide-bore mouthpiece into an open circuit comprised of a heated flowmeter (Fleisch, size \#4; linear to $10.5 \mathrm{~L} \cdot \mathrm{s}^{-1}$; Herwig Surgical, Pittsburgh, PA, USA) and a two-way valve. The flow signal was obtained from a bidirectional transducer (Validyne MP45-22-781; Northridge, CA, USA), amplified, and fed to an A-to-D conversion board (LABLINC, Coulbourn Instruments; Allentown, PA, USA). The signal was digitized at $200 \mathrm{~Hz}$ and then transmitted to a computer (386; Northgate, Minneapolis, MN, USA). A data processing program (Codas; Datag Instruments Inc., Alerum, Oh, USA) was used to display the flow signal on a time-based oscilloscope.

Intrathoracic pressures during cough were recorded from an oesophageal balloon. The balloon (Youngs Rubber Co., Trenton, NJ, USA) was inserted nasally and positioned in the middle third of the oesophagus. The balloon, inflated with $1.0 \mathrm{~mL}$ air, was attached to a transducer (PM5; Statham, Oxnard, CA, USA). Pressure was viewed simultaneously on an oscilloscope (DR-8; Electronics for Medicine, Pleasantville, NY, USA) and on the computer. Proper balloon placement was confirmed by the method of BAYDUR et al. [7]. In preliminary tests, the frequency responses of both the flow and pressure signals were found to be appropriate for this study.

Citric acid (CA) was aerosolized with a nebulizer (DeVilbiss Co., Somerset, PA, USA) placed between the valve and the mouthpiece. Nebulizer output was $0.68 \mathrm{~mL}$. $\min ^{-1}$. 


\section{Protocol}

Coughing voluntarily from FRC. Subjects were coached to cough repeatedly from FRC, varying the intensity of their effort with each cough. After each subject appeared to have mastered this task, a series of at least 20 coughs was recorded. During this series, subjects were encouraged to cough either "gently", "with moderate strength", or "as hard as you can" until a sufficient number of coughs for analysis was recorded. We assumed that generation of a maximal cough effort, like the generation of maximal static muscle pressures, would require repetition. Therefore, to assure production of at least one valid maximal effort, we asked each subject to cough "as hard as you can" at least six times [8].

Coughing with CA stimulation. To test reflex cough, subjects inhaled $10 \%$ CA during tidal inhalation (the nebulizer was activated during every third exhalation). Subjects inhaled CA repeatedly until a sufficient number of coughs for analysis was recorded. Subjects not responding to $10 \%$ CA were given $25 \%$ CA mist.

\section{Data analysis}

Since thoracic gas volume was controlled at FRC during voluntary coughs, simple plots of oesophageal pressure $\left(P_{\text {oes }}\right)$ (the abscissa) versus flow (the ordinate) could be generated from the series of voluntary coughs for each subject.

Analysis of the pressure signal. We observed that frequently the peak positive intrapleural pressure developed during cough (Poes,peak) was recorded many milliseconds after the peak flow. Therefore, we have analysed the pleural pressure driving cough in three ways: 1) Poes,peak; 2) pleural pressure measured simultaneously with maximal flow (Poes,fmx); and 3) the slope of pleural pressure measured at the instant of maximal flow (Poes,slope).

Analysis of the flow signal. Tracings of cough flow and $P$ oes for one subject appear in figure 1 . The three methods were used for analysis of flow. Two were ratios (designated FR1, FR2); the third, a difference (FD). FR1 was computed as follows:

FR1 = peak expiratory flow during cough/maximal flow read from the MEFV curve at the volume from which the compressive phase of cough was initiated.

To obtain the denominator, we devised a program to superimpose each cough or volley of coughs generated by a subject upon the standard MEFV curve for that subject. The program, developed with the use of a commercially available data processing package (Asystant), allowed us to store the MEFV curve and all subsequent volleys of cough in separate files. FRC could be identified in all volume-time tracings. Thus, the computer program could equalize the $x$ - and $y$-axes for the MEFV curve and any volley of coughs selected by the investigators, convert the
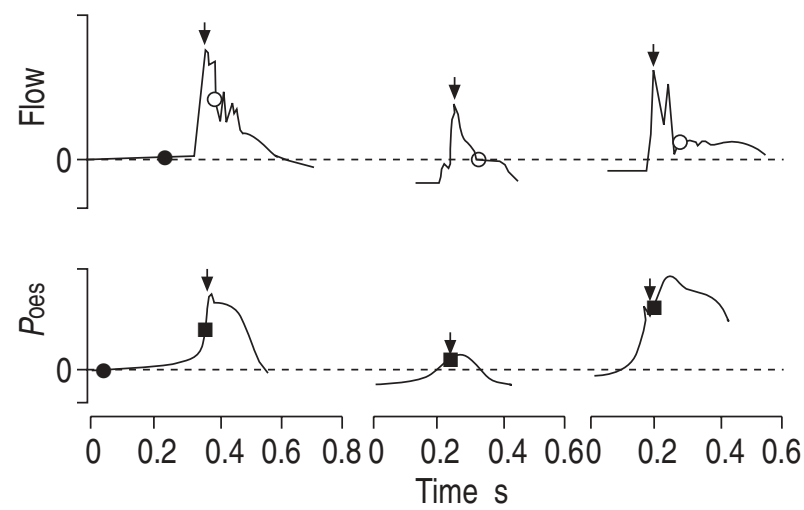

Fig. 1. - Tracings of cough flow and oesophageal pressure ( $\left.P_{\text {oes }}\right)$ from three representative voluntary coughs from one subject. ๑: zero flow and/or pressure; O: flow measured at the plateau, which occurred approximately $30 \mathrm{~ms}$ after peak cough flow; $\mathbf{n}$ : $P_{\text {oes }}$ corresponding to maximal flow. Vertical arrows indicate maximal cough flow and corresponding to that flow $\left(P_{\mathrm{oes}, \mathrm{fmx}}\right)$. Poes,fmx represents the slope $(\mathrm{dp} / \mathrm{dt})$ taken at the times designated by the closed squares. Flow difference $=$ peak flow -plateau flow.

tracings to the flow-volume format, and finally superimpose FRC during cough upon FRC recorded with the MEFV curve. Thus, peak cough flow and flow from the MEFV curve could be read directly from the computergenerated tracing.

FR2 also represented a ratio of peak and MEFV flows, but in this method, both flows were taken from the tracing of cough flow. This ratio is peak cough flow divided by plateau flow, or flow measured approximately $30 \mathrm{~ms}$ after peak flow. FD, the third method, was taken as the difference between peak and plateau cough flows.

Analysis of CA-induced cough. Since thoracic gas volume $(V \operatorname{tg})$ at the time of cough could not be controlled during CA inhalation, the Asystant program was used to compute this volume for each cough. $V$ tg prior to the initiation of thoracic compression for each cough was read from the computer-generated tracing and expressed as a per cent of a predicted value for total lung capacity. Individual plots relating pressure, flow, and/or volume were then generated.

\section{Statistical analysis}

Standard statistical tests, including simple and multiple variable regression analysis and Student's t-test for unpaired and paired data, were performed with a commercially available statistical package [9].

Table 1. - Demographic data

\begin{tabular}{lccccc}
\hline $\begin{array}{l}\text { Subject } \\
\text { No. }\end{array}$ & $\begin{array}{c}\text { Age } \\
\text { yrs }\end{array}$ & Sex & $\begin{array}{c}\text { VC } \\
\% \text { pred }\end{array}$ & $\begin{array}{c}\text { FEV }^{+} \\
\%\end{array}$ & $\begin{array}{r}P_{\text {oes,peak }} \\
\mathrm{cmH}_{2} \mathrm{O}\end{array}$ \\
\hline 1 & 34 & M & 88 & 82 & 214 \\
2 & 23 & M & 94 & 84 & 204 \\
3 & 31 & M & 93 & 81 & 58 \\
4 & 30 & M & 83 & 90 & 78 \\
5 & 32 & M & 117 & 82 & 176 \\
\hline
\end{tabular}

+: expressed as a percentage of VC. VC: vital capacity. FEV1: forced expiratory volume in one second. Poes,peak: the greatest peak oesophageal pressure recorded from all voluntary coughs for each subject; $\%$ pred: percentage of predicted value; M: male. 


\section{Results}

Demographic data appear in table 1. All subjects had normal spirometry. The pressure designated in table 1 represents the greatest $P_{\text {oes }}$ generated by each subject during his sequence of voluntary coughs, i.e. that $P$ oes,peak for each subject associated with the data point appearing furthest along the abscissa in figure 2. These pressures ranged $58 \mathrm{cmH}_{2} \mathrm{O}$ (Subject No. 3) to $214 \mathrm{cmH}_{2} \mathrm{O}$ (Subject No. 1).

Collated data obtained during voluntary cough appear in table 2; individual data depicting the relationship
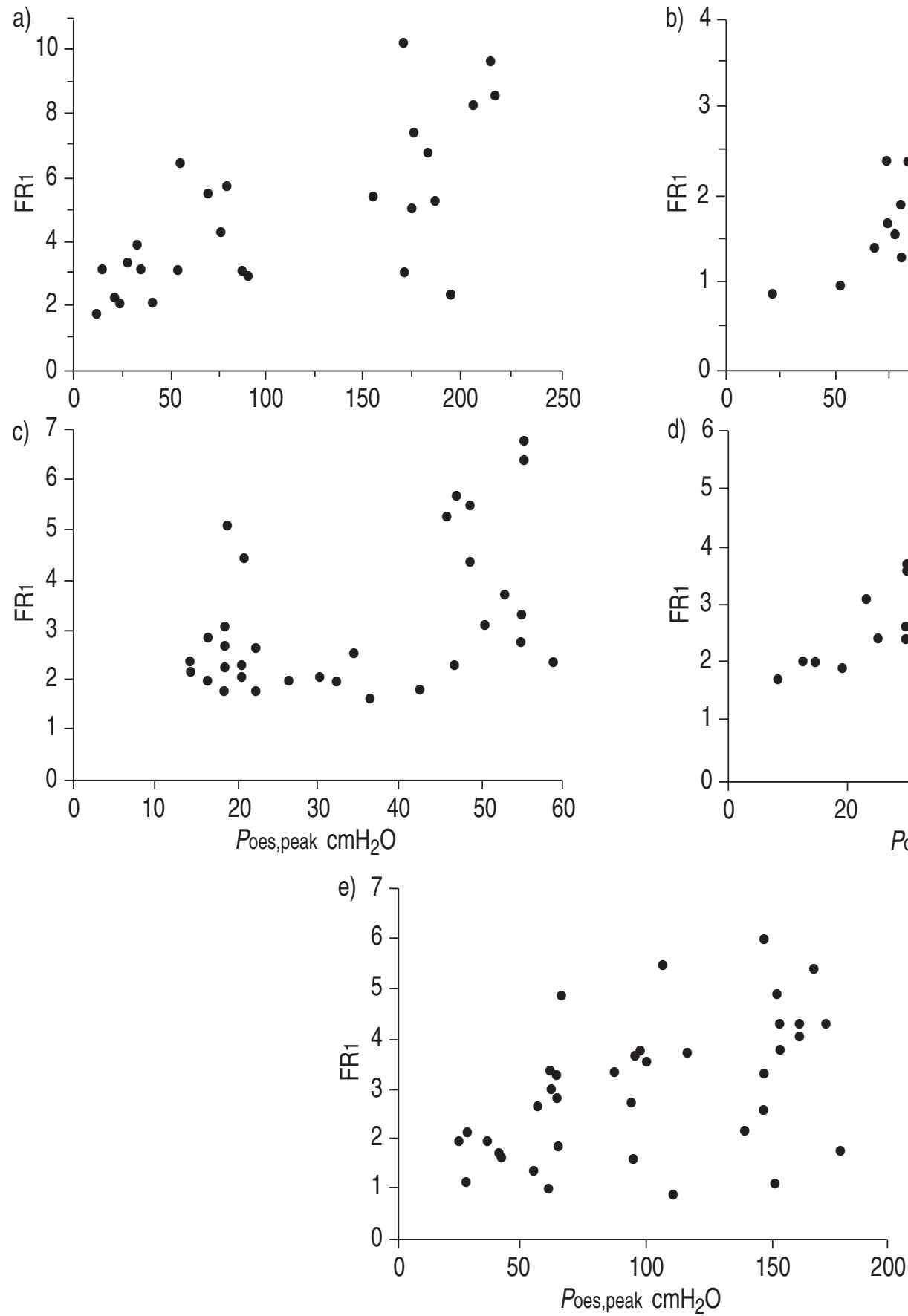

Fig. 2. - Five plots showing data points for the FR1/Poes,peak relationship during voluntary cough for each of the five subjects. a) Subject No. 1; b) Subject No. 2; c) Subject No. 3; d) Subject No. 4; and e) Subject No. 5. FR1: peak expiratory flow during cough/maximal flow read from the maximal expiratory flow-volume curve at the volume from which the compressive phase of cough was initiated.

between $P$ oes,peak and FR1 for each subject appear in figure 2. The number of coughs recorded and available for study, and correlation coefficients for the relationship between $P$ oes,peak and FR1 for each subject appear in table 2. While these latter data are statistically significant for all five subjects, the correlations range from a low of 0.473 (Subject No. 5) to a high of 0.740 (Subject No. 4). The relationship of $P$ oes,peak to FD was significant in all subjects as well; as was that between Poes,peak and FR2, in three of five subjects.

Correlation coefficients for the relationships between $P$ oes,fmx and flow appear in table 2 . Here, data for only
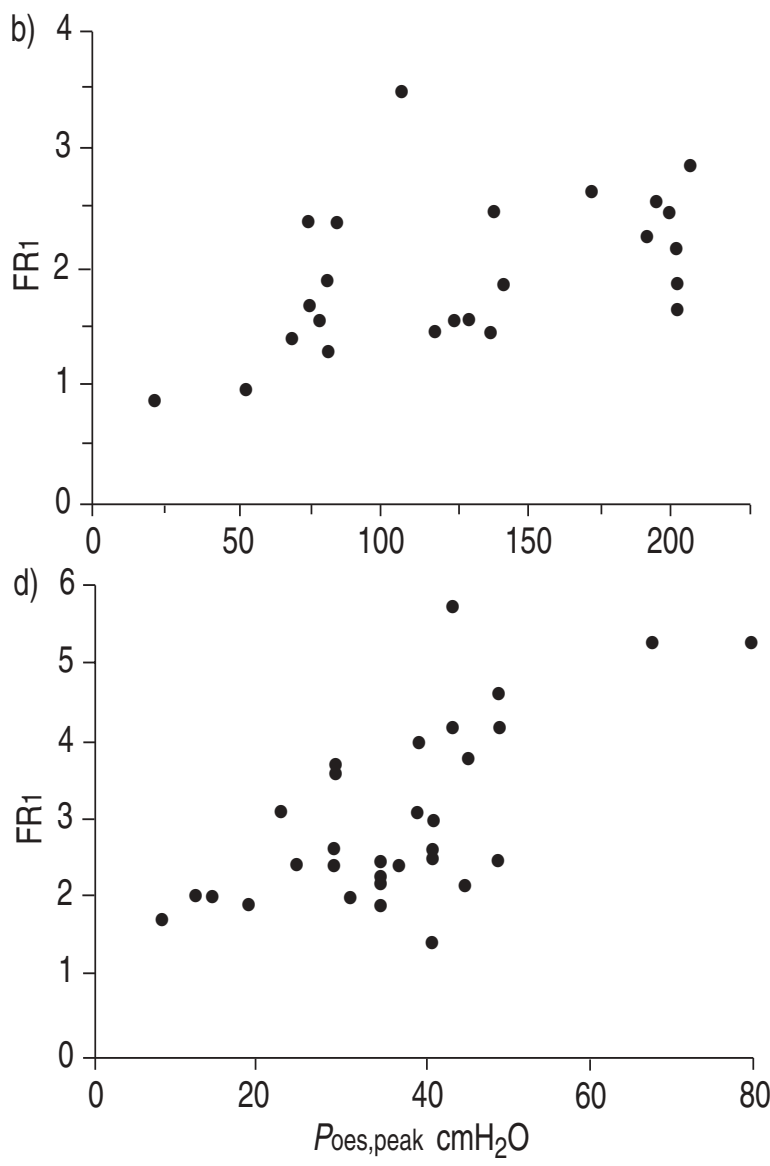
Table 2. - Statistical analysis (by linear regression) of the relationship between driving pressure and the resultant flow for five normal subjects, all coughs having been generated voluntarily from functional residual capacity

\begin{tabular}{|c|c|c|c|c|c|c|}
\hline \multirow[b]{2}{*}{$\begin{array}{l}\text { Subject } \\
\text { No. }\end{array}$} & \multirow[b]{2}{*}{$\mathrm{n}$} & \multirow[b]{2}{*}{ Flow } & \multicolumn{3}{|c|}{ Correlation coefficients } & \multirow[b]{2}{*}{$\begin{array}{c}\text { ýtime } \\
\text { S }\end{array}$} \\
\hline & & & $P_{\text {oes,peak }}$ & $P$ oes,fmx & Poes,slope & \\
\hline \multirow[t]{3}{*}{1} & \multirow[t]{3}{*}{27} & FR1 & $0.582 *$ & $0.483^{*}$ & $0.612 *$ & \multirow[t]{3}{*}{$-0.12 \pm 0.05$} \\
\hline & & FR2 & $0.536^{*}$ & $0.411 *$ & $0.423 *$ & \\
\hline & & FD & $0.634 *$ & $0.425 *$ & $0.459 *$ & \\
\hline \multirow[t]{3}{*}{2} & \multirow[t]{3}{*}{24} & FR1 & $0.487 *$ & 0.207 & $0.522 *$ & \multirow[t]{3}{*}{$-0.11 \pm 0.04$} \\
\hline & & $\mathrm{FR} 2$ & 0.395 & 0.145 & 0.332 & \\
\hline & & FD & $0.499 *$ & 0.224 & $0.449 *$ & \\
\hline \multirow[t]{3}{*}{3} & \multirow[t]{3}{*}{33} & FR1 & $0.490 *$ & 0.032 & - & \multirow[t]{3}{*}{$-0.01 \pm 0.05$} \\
\hline & & $\mathrm{FR} 2$ & 0.319 & 0.134 & - & \\
\hline & & FD & $0.414 *$ & 0.173 & - & \\
\hline \multirow[t]{3}{*}{4} & \multirow[t]{3}{*}{26} & $\mathrm{FR} 1$ & $0.740 *$ & 0.372 & $0.521 *$ & \multirow[t]{3}{*}{$-0.02 \pm 0.03$} \\
\hline & & $\mathrm{FR} 2$ & $0.783 *$ & 0.295 & $0.643 *$ & \\
\hline & & FD & $0.748 *$ & $0.435 *$ & $0.534 *$ & \\
\hline \multirow[t]{3}{*}{5} & \multirow[t]{3}{*}{38} & FR1 & $0.473 *$ & 0.207 & $0.668 *$ & \multirow{3}{*}{$-0.03 \pm 0.06$} \\
\hline & & FR2 & $0.501 *$ & 0.192 & $0.470 *$ & \\
\hline & & FD & $0.495 *$ & 0.173 & $0.693 *$ & \\
\hline
\end{tabular}

FR1: flow ratio, obtained as the quotient of peak cough flow div-ided by flow at functional residual capacity, the latter flow having been obtained during a forced vital capacity manoeuvre performed prior to the cough trials; FR2: flow ratio, obtained as the quotient of peak cough flow divided by plateau flow, approximately $30 \mathrm{~ms}$ following peak flow. FD: flow difference, in litres per second, or the difference between peak cough flow and plateau flow; $P$ oes,peak: peak oesophageal pressure in $\mathrm{cmH}_{2} \mathrm{O}$ developed during each cough; $P_{\text {oes,fmx: }}$ oesophageal pressure at the time of maximal expiratory cough flow; Poes,slope: change in oes-ophageal pressure divided by ýtime at the time $P$ oes,fmx is recorded. ýtime: time elapsed between the development of maximal flow and maximal pressure, expressed as mean $\pm S D$. A negative value indicates maximal flow to have preceded peak pressure. $*$ : $\mathrm{p}<0.05$.

one subject (No. 1) are statistically significant for all flow ratio determinations. Correlations between FD and $P$ oes,slope are also represented in table 2. Data generated for Subject No. 3 were inadequate because for this sub-

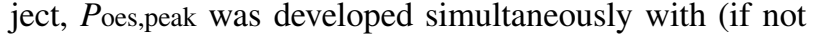
milliseconds before) maximal expiratory flow in many coughs. For this same reason, $P$ oes,slope could not be computed for one of 26 coughs recorded for Subject No. 4 and for seven of 38 coughs of Subject No. 5. Nevertheless, correlation between $P$ oes,slope and flow was significant for all subjects when either FR1 or FD was used to describe flow.

Analysis of the time elapsed between the development of maximal flow and Poes,peak is given in table 2. Poes,peak occurred well after maximal flow in Subjects Nos. 1 and 2 but not in the latter three subjects. Finally, not shown in the table are the relationships between $P$ oes,peak and $P$ oes,slope for four subjects: No. 1, r=0.599; No. 2, r=0.606; No. 4, r=0.577; and No. 5, r=0.424.

\section{Coughs induced by inhaled CA}

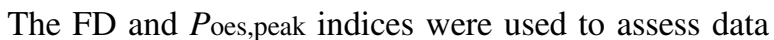
from coughs generated by CA. There were no differences

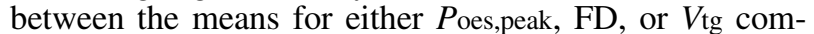
pressed at the initiation of cough during the inhalation of a low versus a higher concentration of CA for any subject. Therefore, data obtained for the two trials were pooled
Table 3. - Statistical analysis (by linear regression) of the relationships between Poes,peak, FD, and volume of thoracic gas $\left(V_{\mathrm{tg}}\right)$ compressed with each cough ( $\left.V_{\mathrm{tg}, \mathrm{comp}}\right)$, all coughs having been generated after the inhalation of citric acid

\begin{tabular}{lcccc}
\hline & \multicolumn{4}{c}{ Correlation coefficients } \\
\cline { 3 - 5 } $\begin{array}{l}\text { Subject } \\
\text { No. }\end{array}$ & $\mathrm{n}$ & FD/Poes,peak & FD/Vtg,comp & $P_{\text {oes,peak } / V \text { tg,comp }}$ \\
\hline 1 & 45 & 0.241 & 0.285 & $0.504^{*}$ \\
2 & 32 & -0.203 & -0.333 & $0.835^{*}$ \\
3 & 46 & $0.536^{*}$ & $0.378^{*}$ & $0.459^{*}$ \\
4 & 46 & $0.303^{*}$ & -0.063 & -0.071 \\
5 & 68 & $0.472^{*}$ & 0.057 & $0.689^{*}$ \\
\hline *: $<<0.05$. & For definitions, see legend to table 2.
\end{tabular}

prior to analysis. The relationships between these variables for each subject appear in table 3 . There is a positive

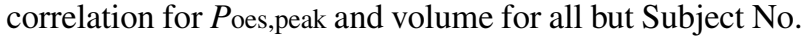
4. By contrast, the relationships of both flow with pressure and flow with volume are more variable.

To replicate the data analysis presented above, which had been performed on the voluntary coughs from FRC, we selected 12-15 coughs generated at or near FRC during CA inhalation for each subject. Only the relationships observed between FD and Poes,peak for subjects Nos.4 (r= $0.52)$ and $5(\mathrm{r}=0.64)$ were statistically significant.

While the volume of gas compressed during a CA-induced cough could not be controlled, it could be measured. We computed the average thoracic gas cough volume for all CA-induced coughs for each subject. The means \pm sD of these volumes were: Subject No. 1, 44 \pm 12 percentage of predicted total lung capacity (TLC); No. $2,38 \pm 7 \%$ pred TLC; No. $3,38 \pm 5 \%$ pred TLC; No. 4 , $43 \pm 6 \%$ pred TLC; and No. 5, 60 $\pm 14 \%$ pred. Both this mean volume and the range of volume over which the subjects coughed (inferred from the standard deviations) differed among the subjects.

Comparison of Poes,peak during CA-induced versus voluntary coughs

To make this comparison, it was necessary to evaluate $P$ oes,peak at FRC, the only cough volume common to both conditions. Thus, for each subject we compared the larg-

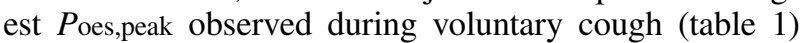
with a representative $P$ oes,peak for cough generated from FRC during CA inhalation. To obtain the latter value, we calculated $P$ oes,peak at FRC from the equations relating these variables for all but Subject No. 4. For that subject, for whom the $P$ oes/volume of thoracic gas compressed with each cough did not exist ( $V$ tg,comp) (table 3$), P_{\text {oes,peak }}$ at FRC was taken as the average of all data points within $\pm 100 \mathrm{~mL}$ of FRC. The greatest $P$ oes,peak recorded from all voluntary coughs for each subject was, on average, mean \pm SEM $146 \pm 33 \mathrm{cmH}_{2} \mathrm{O}$; representative $P_{\text {oes, peak }}$ with CAinduced cough, $157 \pm 15 \mathrm{cmH}_{2} \mathrm{O}$. By this analysis, $P$ oes,peak during voluntary and reflex-induced cough were similar.

\section{Discussion}

This study has two main findings: 1) the quantitative analysis of supramaximal flow during cough cannot be 
used as a precise substitute for Poes to evaluate the generation of force by expiratory muscles during cough; and 2) while $P$ oes,peak is often attained late in the expiratory phase of cough (when flow is determined by lung recoil and upstream airway resistance but not effort), this pressure nevertheless correlates with peak flow during voluntary cough. Two additional observations support the idea that an indirect causal relationship exists between $P$ oes,peak and the pressure driving maximal flow during voluntary cough: 1) flow correlated well with Poes,slope; and 2) $P$ oes,slope correlated with $P$ oes,peak.

\section{The relationship of pressure with flow}

Poes,peak is most likely related to effort because it occurs in most coughs after flow limitation is established. The fact that $P_{\text {oes,peak, }} P_{\text {oes,slope, }}$ and flow are interrelated suggests that $P$ oes,peak represents both effort and, indirectly, driving pressure for flow, and would be an appropriate index with which to investigate cough in subjects with muscle weakness.

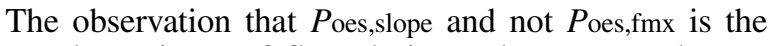
better determinant of flow during voluntary cough supports the notion that peak cough flow is described best by a model involving a derivative of pressure rather than pressure alone. Models relating maximal flow to pleural and airway pressures describe maximal flow during the forced vital capacity manoeuvre [10]. By contrast, maximal cough flow is best described by a model determined in part by the derivatives of both the cross-sectional area of an airway and transmural pressure within that airway [11].

The variability in flow when related to pressure makes the flow ratio index a poor surrogate for Poes,peak. We recognize two possible explanations for this variability. First, the translation of high pressure into maximal flow requires rapid, timely glottal opening [12]. Differences in posterior cricoarytenoid contraction between coughs might explain some of the variability in cough flow when pressure and volume are held constant. Secondly, lung recoil may vary between coughs. This is go because maximal flow during the flow-limited portion of the forced vital capacity may vary slightly depending upon the volume history of the lung [13]. A prolonged period of glottal closure prior to cough might permit stress relaxation of lung parenchyma and, with that, decreased maximal cough flow.

Correlation between $P_{\text {oes,peak }}$ and FD during CA-induced cough was poor in some subjects. This might be explained, in part, by the relatively small ranges of pressure (when compared to the voluntary trials) recorded during volleys of CA-induced coughs. Inspection of pressure tracings showed some volleys of coughs in which elevated pleural pressure was maintained between two or more coughs. For these coughs, $P$ oes slope could not be identified. Perhaps the fact that pleural pressure was constant rather than increasing during some volleys of cough explains the lack of correlation between pressure and flow observed.

Tracings from Subject No. 4, the one subject for whom

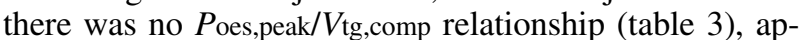
pear in figure 3 . In this volley, maximal cough flow appears to increase with decreasing volume. A possible

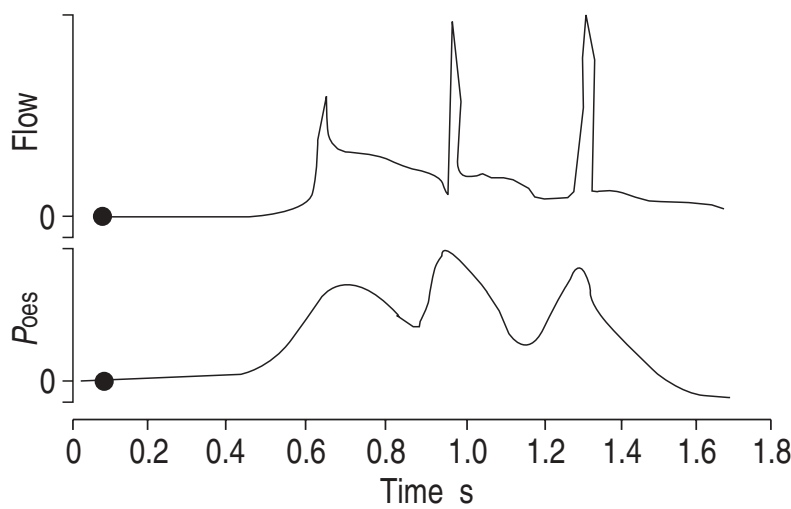

Fig. 3. - Simultaneous tracings of airflow at the mouth and oesophageal pressure $\left(P_{\mathrm{oes}}\right)$, for subject No. 4 after one tidal inhalation of citric acid.

explanation (and a confounding variable for the Poes,peak/ $V$ tg,comp relationship) is the fact that the equal-pressure point moves distally as volume decreases. The volume of gas to be compressed within the trachea thus increases as the volley progresses.

Correlation between volume and pressure during CAinduced cough

Poes,peak decreases with decreasing volume in four out of five of our subjects. This observation is compatible with the fact that, given maximal expiratory efforts at a range of lung volumes, the greatest positive pressure is produced at TLC. That this relationship was not found for Subject No. 4 might be explained by the small range of volume over which this subject coughed $(43 \pm 6 \%$ pred TLC). What determines the volume at which a subject starts to cough or the pattern of his cough (e.g. many bursts of one or two coughs versus few bursts of three or more coughs) is unknown. It has been suggested that reflex-induced cough is "usually preceded by an inspiratory effort" [14]. Finally, a relationship between cough velocity and cough volume has been demonstrated previously in normal subjects coughing voluntarily. However, no pressures were recorded in that study [15].

We conclude from these observations that for studies of the motor limb of the cough reflex, measurements of both airflow and oesophageal pressure are required.

Acknowledgements: The authors thank M.T. Bergen, W. Duran, and S. Soldan for their invaluable technical assistance.

\section{References}

1. Widdicombe JG. Neurophysiology of the cough reflex. Eur Respir J 1995; 8: 1193-1202.

2. Knudson RJ, Mead J, Knudson DE. Contribution of airway to supramaximal expiratory flows. J Appl Physiol 1974; 36: 653-667.

3. Arora NS, Gal TJ. Cough dynamics during progressive expiratory muscle weakness in healthy curarized subjects. J Appl Physiol 1981; 51: 494-498.

4. Szeinberg A, Tabachnik E, Rashed N, et al. Cough capacity in patients with muscular dystrophy. Chest 1988; 94 : 
1232-1235.

5. Leith DE. The development of cough. Am Rev Respir Dis 1985; 131: S39-S42.

6. Morris AH, Kanner RE, Crapo RO, Gardner RM. Clinical Pulmonary Function Testing: A Manual of Uniform Laboratory Procedures. 2nd Edn. Salt Lake City, Intermountain Thoracic Society, 1984: pp. 101-102.

7. Baydur A, Behrakas K, Zin WA., Jaeger M, Milic-Emili J. A simple method for assessing the validity of the esophageal balloon technique. Amer Rev Respir Dis 1982; 126: 273-280.

8. Mcelvaney G, Blackie S, Morrison NJ, Wilcox PG, Fairbarn MS, Pardy RL. Maximal static respiratory pressures in the normal elderly. Amer Rev Respir Dis 1989; 139: 277-281.

9. Ryan BF, Joiner BL, Ryan TA Jr. Minitab Handbook. 2nd Edn. Boston, Duxbury Press, 1985; pp. 200-205, and pp. 236-245.

10. Pride NB, Permutt S, Riley RL, Bromberger-Barnea B.
Determinants of maximal expiratory flow from the lungs. J Appl Physiol 1967; 23: 646-662.

11. Pedersen OF, Lyager S, Ingram RH Jr. Airway dynamics in transition between peak and maximal expiratory flow. J Appl Physiol 1985; 59: 1733-1746.

12. Kuna ST, Vanoye CR. Laryageal response during forced vital capacity maneuvers in normal adult humans. Amer $J$ Respir Crit Care Med 1994; 150: 729-734.

13. D'Angelo E, Prandi E, Milic-Emili J. Dependence of maximal flow-volume curves on time course of preceding inspiration. J Appl Physiol 1993; 75: 1155-1159.

14. Raj H, Singh VK, Anand A, Paintal AS. Sensory origin of lobeline-induced sensations: a correlative study in man and cat. $J$ Physiol 1995; 482: 235-246.

15. Harris RS, Lawson TV. The relative mechanical effectiveness and efficiency of successive voluntary coughs in healthy young adults. Clin Sci 1968; 34: 569-577. 